\title{
Reflexões sobre a classificação de coleções do vestuário: coleções- unidade e coleções-mix
}

Reflections on the clothing collections classification: unit collections and mix-collections

Danielle Silva Simões-Borgiani 


\title{
Reflexões sobre a classificação de coleções do vestuário: coleções- unidade e coleções-mix
}

\author{
Reflections on the clothing collections classification: unit - collections and mix- \\ collections
}

\section{Danielle Silva Simões-Borgiani}

\section{Resumo}

As estratégias comerciais de algumas empresas do vestuário, atualmente, nos levam a uma reflexão acerca do modelo ideal de coleções do vestuário. Sendo assim, este estudo, fruto do doutoramento em Design, propõe uma reflexão sobre coleções do vestuário, tomando como base o surgimento da primeira coleção, a definição de coleção de moda na literatura e segue até as coleções atuais. Como contribuição, apresentam-se duas terminologias para classificar as coleções, conforme foi diagnosticado no estudo, de acordo com características peculiares de cada coleção, bem como favorece $o$ reconhecimento de coleções que não estavam presentes na literatura, não sendo, pois, consideradas coleções.

Palavras- chave: Coleções. Coleçãounidade. Coleção-mix.

\begin{abstract}
The commercial strategies of some companies clothing, currently proposes a reflection on the ideal model of clothing collections. Thus, this study, doctoral fruit in design, offers an analysis of the clothing collections building on the emergence of the first collection, the definition of fashion collection in the literature and will continue until the current collections. As a contribution, presents two terms to sort the collections, as has been diagnosed in the study, according to peculiarities of each collection and favors the recognition of collections that were not present in the literature and thus were not considered collections.
\end{abstract}

Keywords: Collections, Collection- unit Collection- mix. 


\section{Introdução}

Os processos metodológicos, para o planejamento de coleções do vestuário, propõem, do ponto de vista estético, o desenvolvimento de coleções harmônicas: coleções que apresentem tema, formas, estação, padronagens definidas e em sintonia. Seguindo estes procedimentos, espera-se chegar a uma coleção ideal no que se refere à aceitação do público.

No entanto, na prática, encontramos, no mercado, outras formas de desenvolver peças do vestuário e que, se analisadas a partir dos procedimentos citados anteriormente, não seriam coleções do vestuário. Embora sejam lidas como não sendo coleções, são peças aceitas e que vendem bem. São grupos de peças disponíveis num mesmo ambiente para consumo e que apresentam padronagens, formas, estilos e temas distintos.

Muitas vezes as lojas anunciam tais grupos como coleção inverno, coleção verão, coleção carnaval ou outra temática, mesmo não havendo coerência no estilo, formas e padronagens. Muitas vezes existe um julgamento, baseado na literatura, de que, se não for harmônico, não é coleção.

Essa percepção apontada aqui foi o que motivou a tese de doutoramento, ou seja, uma investigação sobre coleções do vestuário e a contemporaneidade. $\mathrm{O}$ estudo do doutoramento apresenta uma análise sobre estratégias de gestão de coleções, e aqui, neste texto, apresentaremos algumas considerações traçadas, a fim de classificar as coleções contemporâneas.

\section{Charles Worth e a coleção de moda pioneira}

A primeira coleção de moda da história do vestuário advém do estilista Charles Worth e foi concebida como um conjunto de objetos da mesma natureza. Era uma reunião de peças apresentadas num momento a um grupo de mulheres da sociedade. Assim, instituiu-se, também, o primeiro desfile de moda, utilizado como estratégia de divulgação e desejo para o público alvo (LAVER, 2002; COSGRAVE, 2012).

Costureiro do início do século XX, Charles Worth abriu sua Maison em Paris e causou uma reviravolta no fazer roupas da época. Worth foi o primeiro a confeccionar vestidos pensando nas clientes que eram seu público-alvo. Ele também escolheu mulheres com tipo físico igual ao das suas clientes para desfilarem suas peças.

Para Cosgrave (2012):

\footnotetext{
A contribuição de Worth para a história da moda é lendária. Ele é considerado o criador da haute couture ou alta-costura, isto é, roupas finas feitas sob medida. [...] Worth produziu outras inovações. Ele foi o primeiro estilista a produzir uma coleção completa de roupas sazonais, em vez de peças isoladas, ao acaso. (COSGRAVE, 2012. p 196).
} 
Worth foi referência também por instituir a profissão modelo, uma vez que ele convidou, para vestirem as peças no lançamento da coleção, mulheres de tipo físico similar à possível compradora. Vale lembrar que estas peças atendiam os gostos particulares de cada uma das possíveis compradoras, dessa forma, poderiam não estar em harmonia entre si. Era uma reunião de vestidos, apenas. As peças de Charles Worth (figura 01) carregam consigo sempre detalhes riquíssimos de bordados e formas que reforçam a delicadeza e feminilidade, conforme vemos abaixo:

Figura 1. Peças de Charles Worth

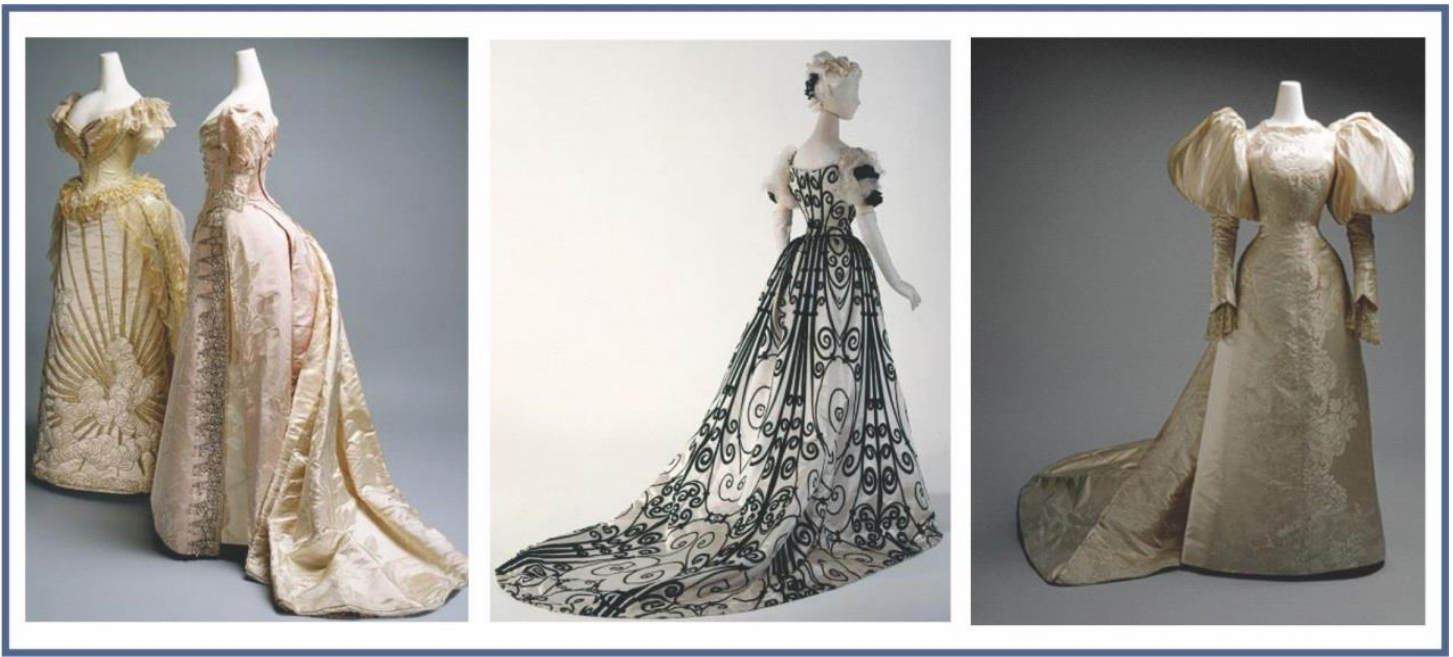

Fonte: The metropolitan museum of art.

Percebe-se que o surgimento da primeira coleção foi uma forma estratégica de movimentar o consumo na época e reposicionar o estilista o qual deixou de ser o simples costureiro que reproduzia as demandas e passou a ser o estilista que ditava moda. A partir daí, surgiram várias maisons, bem como o desejo de participar dos desfiles de moda, para conhecer as referências de cada estação.

Diante desse levantamento sobre o surgimento da primeira coleção de moda e em relação ao que é tratado na academia como coleção do vestuário, nos questionamos sobre o que é realmente uma coleção. Claro, deve-se considerar que, naquele momento em que Charles Worth instituiu as coleções de moda, não havia tanta concorrência, as configurações econômicas eram outras e o entendimento da sociedade também. Antes de chegarmos à definição de coleção - conforme se expressa na academia - vamos visitar as definições de coleção enquanto terminologia. 


\section{E o que é uma coleção?}

Segundo Siplestein \& Blelloch (1991), uma coleção é um conjunto de objetos vistos como um todo. É uma reunião de objetos similares. Cormen et all (2009) definem coleção como conjunto de produtos com os mesmos atributos ou características. Gonçalves (2000); Ferreira (2010); Miranda (2007) e Houaiss \& Villar (2009) trazem a definição de que uma coleção é a reunião de objetos de mesma natureza ou objetos escolhidos por sua beleza, raridade, valor documentário ou preço, como uma coleção de selos ou uma coleção de quadros, ou, ainda, um conjunto de modelos para uma temporada.

Considerando essas definições para coleção, de forma ampla, podemos compreender coleção como conjunto de objetos com alguma similaridade ou unidade (e.g.: coleção de roupas, coleção de livros, coleção de verão, coleção de sapatos, coleção de jornais).

Comumente a palavra coleção é usada no sentido apresentado acima. Principalmente quando se refere a algo de posse pessoal. É comum as pessoas se referirem a seus conjuntos de sapatos, relógios e quadros como coleções. Neste caso, a coleção é um conjunto de objetos similares que a pessoa foi adquirindo por um período.

Watt e Brown (2001) corroboram com as definições anteriores para coleção, entendida como conjunto ou grupo de objetos e propõem a classificação das coleções de acordo com seus produtos ou objetos. Para esses autores, a coleção pode ser homogênea ou heterogênea.

Coleções homogêneas são aquelas que contêm apenas elementos de determinados tipos. Consideram-se coleções heterogêneas aquelas que contêm elementos de tipos diferentes (WATT \& BROWN, 2001).

A terminologia coleção usada na contemporaneidade, para referir-se à coleção de produtos da moda, tem diferenças em relação as aqui postas. Estas, constantes deste tópico, apresentam um caráter de coleção como reunião de produtos de mesmas características. E corroboram com as coleções de Charles Worth, entendidas como reunião de vestidos com diferentes estilos, para diferentes clientes.

\section{A definição de coleção no design de moda}

$\mathrm{Na}$ formação do designer de moda e na prática de ações de marketing de marcas do vestuário ou acessórios, uma coleção é tratada como conjunto de peças projetado 
para uma estação, seguindo uma tendência e que possui uma harmonia entre si (elementos de estilo, cores e formas). Esses produtos são desenvolvidos através de metodologias de criação de coleções que incluem as pesquisas de público-alvo, mercado, tendências em cor, forma e texturas, mix de produtos e mix de estilos (TREPTOW, 2013).

Ao realizarmos um levantamento de autores e suas considerações sobre coleções, percebemos que sempre se reforça nas definições que as coleções devem ter unidade e harmonia. Jones (2011), em sua explanação sobre coleção, versa sobre os princípios de design como elementos de estilo da coleção que vão dar unidade e harmonia a mesma. A coleção deve ter coerência na estética e harmonia.

Para Mendes (2010):

[Uma coleção] É um conjunto de peças do vestuário apresentado ao público com dois objetivos bastante distintos: lançamento para estabelecer tendências ou para disponibilizar os produtos no mercado. Em qualquer dos casos, a coleção tem que apresentar looks harmônicos quanto ao seu conjunto. (MENDES, 2010, p. 134)

Já, Rech (2002; 2003; 2012) define coleção pela harmonia e sazonalidade. Rech (2002; 2003; 2006; 2012) define coleção como um conjunto de produtos harmônicos do ponto de vista visual ou comercial e com fabricação e entrega para determinada época do ano.

Navalon (2008) afirma que uma coleção é a síntese do painel imagético construído. Nele podem estar colagens e sobreposições com fotografias, recortes, postais, desenhos e anotações. Em sendo uma síntese da mesma fonte de referência, possivelmente elementos comuns nas peças se repetirão, gerando uma harmonia visual.

Diante das considerações dos autores citados anteriormente e levando em conta alguns tipos de empresa, já levantamos alguns questionamentos para propor reflexões: para uma empresa que só produz camisas polos de diferentes padronagens e detalhes: neste caso, por não formar looks harmônicos, este tipo de conjunto não seria considerado coleção? Ou a coleção estaria em criar padronagens muito parecidas entre as camisas polo? E como fica, se eles precisam de diversidade para atender diferentes compradores? Elas seriam uma coleção por ser uma reunião de produtos 
com os mesmos atributos (camisas)? Como a indústria da moda encara estes produtos? São preteridos por não serem harmônicos?

Frings (2012) traz uma definição para coleção apontando que existe o conceito de coleção e de grupos. Existem grupos de roupas que formam uma coleção. Cada grupo tem um tema definido que pode se basear num tecido, cor ou tendência. Cada grupo é de um conjunto de roupas de mesmo estilo ou para mesma ocasião: vestidos de festa, ternos, sportwear, entre outros. Para criar a unidade da coleção, o autor defende que cada grupo tem elemento em comum que vai se repetir e dar unidade às peças e coleção.

Esse levantamento de definiç̧ões nos conduz a várias reflexões. As definições apresentadas até o presente momento do entendimento de coleções no Design de Moda corroboram entre si. Treptow (2013) reforça que as coleções devem ser coerentes e expressar os seguintes aspectos: perfil do consumidor, identidade ou imagem da marca, tema da coleção, proposta de cores e materiais. A mesma autora ainda reforça que muitas empresas não possuem este conceito e que os produtos desenvolvidos são uma adaptação de tendências, mas sem coerência. Ainda, em continuidade, versa sobre a dificuldade de criar vitrines, fazer catálogo de mostruário, fazer mix de peças entre tops ${ }^{1}$ e bottons ${ }^{2}$.

A definição de Treptow (2013) é abrangente quanto à coleção e coerência ao considerar o perfil do consumidor, imagem da marca, tema, materiais e cores. No entanto, ao relacionarmos esta definição às coleções do vestuário de empresas que fornecem para outras, verificamos um desencontro: ou estas empresas não produzem coleções, ou elas vão produzir coleções extremamente diferentes em tema, cor, materiais, uma vez que fornecem para marcas com públicos distintos e regiões distintas.

Nesse sentido, questionamos: a concepção anterior de coleção estaria tratando da definição de coleção para empresas com ponto de venda? E aquelas que vendem multimarcas e compram de vários fornecedores? Não teriam coleções? Como devem fazer vitrines, se os produtos vêm de marcas diferentes, consequentemente temas, conceitos e formas diversificadas? Não deveriam anunciar coleção verão ou coleção inverno? Ou seria outro tipo de coleção?

\footnotetext{
1 Tops - partes de cima das peças do vestuário.

${ }^{2}$ Bottons - partes de baixo das peças do vestuário.
} 
A definição de Liger (2012) deixa a harmonia um pouco de lado e abre espaço para outra forma de entender coleções: define uma coleção de moda como um conjunto ou grupamento de produtos, ou série que foram elaborados em forma de modelos e que têm uma relação entre si. Ainda complementa que a coleção pode ser de roupas, calçados, acessórios, óculos, entre outros. Ou seja, segundo Liger (2012), deve

haver uma relação entre as peças. No entanto, esta relação não está determinada como estética e harmônica. Pode ser uma série de produtos iguais, por exemplo: uma série de vestidos. Esta definição é a que adotamos neste estudo, considerando que a harmonia estética pode vir ou não numa coleção. Ela se aproxima da definição de coleção que apresentamos inicialmente, independentemente de ser de produtos da moda (vestuário).

\section{E o cenário atual de vendas, consumo, criação e mercado?}

Segundo Simões-Borgiani (2014), algumas peculiaridades do mercado devem ser observadas e auxiliam no entendimento das coleções na contemporaneidade. Por não haver mais na moda um estilo único a ser seguido em determinado período, cada vez mais a diversidade de estilos (leia-se formas, cores e padronagens) estão disponíveis ao mesmo tempo nas araras das lojas. Alguns até permanecem por várias estações. $\mathrm{O}$ consumidor atual escolhe diariamente que estilo irá vestir e expressar. Existe uma facilidade muito grande de se projetar como se quer. E isso virou reflexo na indústria criativa da moda.

Partindo deste olhar, várias confecções e pontos de venda já oferecem uma diversidade de estilos e formas para consumo. Cada vez mais, lojas diversificadas aparecem no mercado. São geralmente grandes com diversas marcas e estilos no mesmo ambiente. Elas atendem um público diversificado. E montam coleções com este mix de produtos e estilos.

$\mathrm{Na}$ verdade, essa opção por diversificar produtos no intuito de atingir mais pessoas e, consequentemente, vender mais, constitui-se em ferramenta estratégica de mercado. Enquanto algumas empresas preferem fazer coleções harmônicas, de acordo com as definições de coleções para moda e direcionam para um único público, outros preferem atingir vários públicos e consequentemente com uma grande diversidade de produtos. A harmonia, nesse caso, não seria estética, ligada ao conceito, mas sim à 
estação ou período do ano para o qual as peças se destinam, independente de temas ou estética de cada uma (SIMÕES-BORGIANI, 2014).

Mendes; Sacomano \& Fusco (2006a; 2006b) apontam que a estratégia é uma vantagem competitiva de empresas e, por estar diretamente ligada ao mercado, deve sempre ser atualizada em relação a concorrentes, a fim de atingir o sucesso.

Dessa forma, a flexibilidade empresarial é obrigatória, para que empresas respondam rapidamente às alterações competitivas de mercado (PORTER, 2005).

Em nossa reflexão, essa flexibilidade empresarial é o que tem mobilizado muitas empresas a fazerem coleções tão diversificadas/flexíveis, já que elas querem atingir diversos públicos. Nesse sentido, elas produzem coleções diversificadas ou estratégicas para venda.

Diante dessas reflexões, Simões-Borgiani (2014) propõe terminologias para classificar coleções, considerando que os dois tipos seriam coleções. Ou seja, reconhecemos, neste estudo, que existe outro modelo de coleção de vestuário que não deixa de ter valor pelo fato de não ser harmônico. E são coleções que acontecem como aconteceram as primeiras coleções de moda: como reunião de peças de estilos diversos, para público diversificado, mas postos para a mesma estação - nos referimos aqui à primeira coleção de moda da história do estilista Charles Worth.

\section{Coleção unidade e coleção mix}

As coleções apresentadas na literatura, em sua maioria, carregam o viés do estilismo ou da coleção autoral: aquela em que se faz defesa do tema, defesa das formas, defesa das tendências, cores e estampas.

Do ponto de vista didático, a identificação das coleções estudadas/aprendidas deverá ser de todas as coleções possíveis na prática profissional. Assim, a ideia artística de uma coleção em perfeita harmonia com cor, tema, público-alvo, mix de peças é rompida diante das realidades e necessidades estratégicas de mercado (SIMÕESBORGIANI, 2014).

SIMÕES-BORGIANI (2014) apresenta dois tipos de coleções quanto aos seus produtos: coleção homogênea e coleção heterogênea.

A coleção homogênea ou coleção-unidade refere-se a coleções em que se tem plena harmonia entre um estilo definido, tema ou conceito, estação a que se destinam, 
formas, cores e padrões. Geralmente é uma coleção de empresas de grife ou marcas e que é vendida em lojas próprias. São coleções pequenas, mais características de uma coleção autoral (SIMÕES-BORGIANI, 2014).

Já, para o outro tipo de coleção investigado no estudo, a autora apresenta a seguinte definição:

\begin{abstract}
A coleção heterogênea ou coleção mix refere-se a coleções em que se apresentam vários estilos, cores, formas, geralmente está posta para uma mesma estação e geralmente é grande em quantidade de modelos. O perfil de empresa que trabalha com estas coleções é aquele que vende para alimentar outras lojas, ou vende para sacoleiras ou são grandes marcas que trabalham no perfil magazines ou lojas de departamentos. É uma definição mais contemporânea para a prática das coleções do vestuário, considerando que hoje, o estilo pessoal é muito dinâmico, as compras das pessoas também serão. Mesmo para empresas com ponto de venda e valor de marca agregado, foi percebido o desenvolvimento de coleções com características de heterogeneidade (SIMÕES-BORGIANI, 2014 p. 130).
\end{abstract}

Aponta-se, dessa forma, que diversidade de modelagens, padronagens e estilo num mesmo ambiente de loja aparecem como estratégia competitiva, diante do novo cenário do ser como agente decisório de seu estilo diário.

Nenhuma das definições de coleção minimiza o valor de outra. Na verdade, as duas permitem que seja dado o devido valor a cada uma das coleções. E, inclusive, propõem uma reflexão no sentido de se desenvolverem coleções de maneira estratégica (SIMÕES-BORGIANI, 2014).

\title{
Considerações Finais
}

As reflexões aqui apresentadas visam a contribuir para um novo olhar sobre o planejamento de coleção e o cenário atual de mercado. Sem dúvidas, cabe a inferência de que também foi estratégia de mercado a instituição de coleções do vestuário como aquelas que eram harmoniosas, preocupação esta que não havia no início, quando surgiram as primeiras coleções. Ou seja, é preciso refletir que o mercado sempre será um grande norte para as estratégias que envolvem coleções e, assim, será possível definir qual melhor coleção trabalhar, se coleção unidade ou se coleção mix.

Em qualquer área de estudo, a atualização contínua, a pesquisa e novas reflexões nos permitem rever métodos, processos e definições. Justamente por este motivo, nunca se encerram. Este artigo aborda o que foi construído como tese para doutoramento, concluído em 2014, mas com certeza deverá sempre ser investigado para se adaptar às 
necessidades do momento. Nenhuma teoria se encerra nela. Estudos fenomenológicos ou descritivos devem sempre ser considerados em seu tempo e servirem de reflexões para tempos à frente.

A investigação sobre coleções, aqui tratada, propõe uma identificação dos perfis de coleção hoje existentes no mercado pernambucano, onde se configurou a pesquisa. No entanto, ao refletir sobre o assunto e começar a analisar coleções de grandes marcas, percebemos que o mix também se encontra nelas. Essas mudanças nas coleções, percebidas durante o estudo, não foram encontradas na literatura da área atual. Um objeto de estudo novo e pouco explorado.

Simões-Borgiani (2014) aponta que o fato de a diversidade de coleções existentes não constar da literatura, acaba por gerar uma forte crítica àquele que diz que só faz coleção quem a produz de acordo com harmonia, conforme prescrita na literatura. Ou seja, coloca à margem as coleções de muitas empresas, desqualificando a coleção estratégica que elas trabalham.

A coleção que já se encontra na literatura (harmônica) faz a empresa caminhar para uma imagem da marca mais forte, ou seja, uma identidade consolidada. Por outro lado, as coleções estratégicas contribuem para que a empresa se sustente num mercado tão concorrido.

A aleatoriedade da coleção é o caminho para uma coleção heterogênea que atinge mais de um estilo de comprador. É uma coleção muito mercadológica. Sem dúvida, por tanta variação de modelos e materiais, é uma coleção trabalhosa, grande e necessita de muita gestão. A gestão, aqui posta, refere-se tanto à coleção como ao arranjo produtivo na confecção, ou seja, na linha de produção.

Entender os tipos de coleção e se adequar as necessidades de mercado, é a melhor forma para escolher como se trabalhar no cenário atual.

Artigo recebido em Julho de 2015. Aprovado em Setembro de 2015 DOl:http://dx.doi.org/105965/1982615x08172016238

\section{Referências}

CORMEN, T. H.; LEISERSON, C. E.; RIVEST, R. L.; STEIN, C. Introduction to algotithms. 3 ed. Massachusetts: Massachusetts Institute of Technology, 2009. 
COSGRAVE, B. História da indumentária e da moda. Das antiguidades aos dias atuais. Tradução de Ana Resende. Barcelona: Gustavo Gil, 2012.

LAVER, J. A roupa e a moda: uma história concisa. São Paulo: Companhia das letras, 2002.

FERREIRA, A. B. H. Dicionário Aurélio da Língua Portuguesa. Edição histórica 100 anos. São Paulo: Positivo, 2010.

FRINGS, G. S. Moda: do conceito ao consumidor. Tradução de Marina Belloli. 9 ed. Porto Alegre: Bookman, 2012.

GONÇALVES, J. E. L. As empresas são Grandes Coleções de Processos. In: RAE Revista de Administração de Empresas, São Paulo, v. 40, n.1, p. 6-19. Jan./mar., 2000.

HOUAISS, A.; VILLAR, M.S. Dicionário Houaiss da Língua Portuguesa. Rio de Janeiro: Objetiva, 2009.

JONES, S. J. Fashion Design - manual do estilista. Tradução de Iara Biderman. São Paulo: Cosacnaify, 2005.

JONES, S. J. Fashion Design - manual do estilista. Tradução de Iara Biderman. São Paulo: Cosacnaify, 2011.

LIGER, I. Moda em 360 graus: design, matéria-prima e produção para o mercado global. São Paulo: Editora Senac. São Paulo, 2012.

MENDES, F. D. Um estudo comparativo entre as manufaturas do vestuário de moda do Brasil e da Índia. Tese de doutorado (Doutorado em Engenharia de Produção). Universidade Estadual Paulista, São Paulo, 2010.

MENDES, F.D.; SACOMANO, J. B.; FUSCO, J. P. A. Planejamento e Controle da produtividade na manufatura do vestuário de moda. In: Simpósio de Administração, Operações e Logística, 9, 2006, São Paulo, Anais, São Paulo, 2006 .

MENDES, F.D.; SACOMANO, J. B.; FUSCO, J. P. A. Manufatura do Vestuário de Moda - o PCP como estratégia competitiva. In: Encontro Nacional de Engenharia de Produção, 26, 2006, Fortaleza, Anais, 2006 b.

MIRANDA, A. C. C. Desenvolvimento de coleções em bibliotecas universitárias. In: Revista Digital de Biblioteconomia e Ciência da Informação, Campinas, v. 4, n. 2, p. 1-19, jan./jun., 2007.

NAVALON, E. Design de Moda: interconexão metodológica. Dissertação de Mestrado (Mestrado em Design) - Universidade Anhembi Morumbi. São Paulo, 2008.

PORTER, M. E. Estratégia Competitiva. Rio de Janeiro: Campus, 2005. 
RECH, S. R. Moda: por um fio de qualidade. Florianópolis: UDESC, 2002.

RECH, S. R. Conceito de Produto de Moda. Actas de Diseño, v. 13, p. 187-191, 2012.

RECH, S. R. The Fashion Design Manager: global market differentiating. (Anais...) III International Textile and Apparel Conference. Rio de Janeiro: Cetiqt, 2003 (1 Cdrom).

RECH, S. R. Cadeia produtiva da moda: um modelo conceitual de análise da competitividade no elo confecção. Tese de doutorado (Doutorado em Engenharia de Produção). Universidade Federal de Santa Catarina. Florianópolis, 2006.

SIMÕES-BORGIANI, D. S. Um estudo sobre as estratégias de gestão de coleções do vestuário em seis empresas de Pernambuco. Tese de doutorado (Doutorado em Design). Universidade Federal de Pernambuco, Recife, 2014.

SIPLESTEIN, J.M.; BLELLOCH, G. E. Collection-oriented languages. In: Proceedings of the IEEE, Pittsburg, USA, v. 79, n. 4, p. 504-523, 1991.

TREPTOW, D. Inventando moda: Planejamento de coleções. 3ed. Brusque: do autor, 2005.

TREPTOW, D. Inventando moda: Planejamento de coleções. 3ed. Brusque: do autor, 2013.

WATT, D. A.; BROWN, D. Java Cllections: An Introduction to Abstract Data Types, Data Strcture and Algarithms. USA: Wiley, 2001. 